Review

\title{
Genomic Biomarker Surveillance in the Care of Solid Organ Transplant Recipients: An Update for the General Clinician during the Coronavirus (CoVid-19) Pandemic
}

\author{
Allison Ramsey ${ }^{1,}{ }^{*}$, Christine Natori ${ }^{2}$, Kristen Cisneros ${ }^{3}$, David J. Ross ${ }^{4}$, Abbas Ardehali ${ }^{5}$
}

1. Ronald Reagan-UCLA Cardiothoracic Transplant Program, Division of Pulmonary, Critical Care \& Immunology, David Geffen-UCLA School of Medicine, USA; E-Mail: aramsey@mednet.ucla.edu

2. Department of Nursing, Ronald Reagan-UCLA Medical Center, USA; E-Mail: Cnatori@mednet.ucla.edu

3. Medical Science Liaison CareDx, Inc., South San Francisco, USA; E-Mail: Kcisneros@caredx.com

4. Transplant Molecular Diagnostics, CareDx, Inc., South San Francisco, USA; E-Mail: djrossmd30@gmail.com

5. Cardiothoracic Transplant Program, Ronald Reagan-UCLA Medical Center, David Geffen-UCLA School of Medicine, USA; E-Mail: Aardehali@mednet.ucla.edu

* Correspondence: Allison Ramsey; E-Mail: aramsey@mednet.ucla.edu

Academic Editor: Haval Shirwan

OBM Transplantation

2020, volume 4, issue 2

doi:10.21926/obm.transplant.2002107
Received: March 27, 2020

Accepted: April 29, 2020

Published: May 06, 2020

\begin{abstract}
Biomarker surveillance after solid organ transplant is an advancing field with promise for further elucidation through high-throughput analyses and "omics" technologies. To date, Gene Expression Profiling (GEP; AlloMap ${ }^{\circledR}$ ) is the only FDA-cleared genomic assay as surveillance for moderate-severe TCMR versus allograft quiescence after heart transplantation. Clinical validity and utility, however, have been recently established after kidney and heart transplantation, for analysis of donor-derived cell-free DNA in the assessment for potential "Allograft Tissue Injury" that may occur during diverse processes such as T-Lymphocyte mediated (TCMR) or Antibody-mediated (ABMR) allograft rejection or allograft-associated infection. These genomic analytes are currently being explored and
\end{abstract}

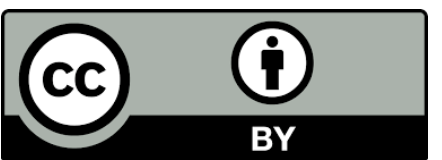

(C) 2020 by the author. This is an open access article distributed under the conditions of the Creative Commons by Attribution License, which permits unrestricted use, distribution, and reproduction in any medium or format, provided the original work is correctly cited. 
evaluated across the spectrum of solid organ transplantation and the focus of numerous robust clinical transplant study registries. "Multi-Modality Surveillance" is currently firmly established within the armamentarium and practice algorithms of the transplant center specialist. However, such diagnostics which are performed on peripheral blood samples obtained during routine laboratory surveillance are now available and widely applicable during the inevitable clinical transition in care that is increasingly relegated to the General Practitioner. Noninvasive Biomarker assessment may prove invaluable for surveillance to thereby avoid the predominance of invasive protocol biopsy procedures. Further, during times of increased risk of infectious contagion exposure, such as the SARS-CoV-2 (CoVid-19) pandemic, laboratory Biomarker surveillance may prove invaluable in deferring routine scheduled office or clinic appointments and the inherent exposures.

\section{Keywords}

Organ transplant; molecular diagnostics; biomarker; rejection; surveillance

\section{Introduction}

In 2018, the 36,527 solid organ transplants performed in the U.S. achieved an annual record for the sixth straight year [data from United Network for Organ Sharing (UNOS)], while the use of organs from both deceased and living donors, increased 5\% over 2017. Approximately 10,700 deceased donations represented this "gift of life". An increase in deceased donation relates to an increased usage of donors with a broader spectrum of "acceptability criteria" while approximately $20 \%$ of donations occurred after circulatory death (DCD) as opposed to brain death. Approximately $9 \%$ of deceased donor kidney transplants involved organs with a Kidney Donor Profile Index (KDPI) score $\geq 86$, which may be associated with shortened allograft survival as opposed to a low KDPI donor. Further, an increased usage of Hepatitis C positive donors in solid organ transplant, has been anticipated to further increase donor availability and shorten "wait list times" for critically ill recipients [1-3]. Nevertheless, a sobering 120,000 patients in the U.S. remain on the UNOS transplant list including more than 100,000 ESRD patients.

Despite clinical advances in solid organ transplantation, long-term allograft and patient survival have been hampered by development of acute or chronic rejection, which may relate to either TLymphocyte (TCMR) mediated and/or antibody-mediated (ABMR) allogeneic immune responses [4-7]. Further, increasing evidence has implicated Th-17 and Interleukin- 6 biology in pathogenesis of acute and chronic allograft rejection [8, 9]. Intriguing also, has been the recent elucidation of auto-immune in addition to the well appreciated anti-HLA allo-immunologic responses, that may contribute to the pathobiology of chronic allograft rejection $[6,10]$. Auto-antibodies may develop as directed towards endothelial cells (EC), Angiotensin-2 type-1 receptor (AT1R) and Major Histocompatibility Complex class I chain-related molecule A (MICA) [11-15]. Furthermore, although current solid -phase assays, which are routinely employed as surveillance post-transplant, can detect donor-specific HLA Class I \& II allo-antibodies (DSA); the non-HLA or auto-antibodies that also can contribute to significant allograft injury, are not detected. Short and intermediateterm allograft survival rates have varied significantly according to the transplanted organ - Heart: 
(1-year ) 90.3\%, (3-year ) 84.7\%, (5-year) 79.6\%; Liver: (1-year) 91.2\%, (5-year ) 78.0\%; Kidney: (10year) 49.7\%; Lung: (1-year) 89.2\%, (5-year) 55.6\% [16-19].

Currently, more than 220,000 patients reside in the U.S. with a functioning kidney transplant and burgeoning post-transplant volumes have been observed with the other solid organs [17]. Therefore, increasingly, recipients are required to transition part if not all of their medical care from the transplant center back to the general practitioner. To this end, novel non-invasive plasma biomarkers have been pioneered and implemented, based on demonstrated clinical validity and utility, as "allograft surveillance" for either supporting "quiescence" within the allograft versus suggesting potential complications such as TCMR, ABMR or allograft-associated infection. Indeed, now novel genomic based blood tests, can query the allograft recipient, such as by "Gene Expression Profiling" (GEP) (AlloMap ${ }^{\circledR}$ ) for post-heart transplant recipients that can raise clinical suspicion for potential TCMR versus quiescence of the allograft. Plasma donor-derived cell-free DNA (dd-cfDNA) (AlloSure ${ }^{\circledR}$; Prospera ${ }^{\circledR}$ ), can signal potential allograft "tissue injury" due to either rejection (TCMR or ABMR) or allograft-associated infectious complications. The following summarizes the availability and clinical utility of such diagnostic testing, which is currently in the armamentarium of both the transplant team and general practitioner alike.

\section{Gene Expression Profiling (GEP) (AlloMap ${ }^{\circledR}$ ) for Orthotopic Heart Transplant (OHT) Surveillance of TCMR versus Quiescence}

After the pivotal completion of the Human Genome Project, subsequent novel queries were permitted into the relationships between genomic sequence variability, transcriptomic patterns of gene expression and proteomic patterns as contributing to the diverse cellular and tissue phenotypes. [20, 21]. Gene Expression Profiling (GEP) [AlloMap ${ }^{\circledR}$ ] was the first biomarker diagnostic and prognostic test, performed on peripheral blood mononuclear cells (PBMC) that had achieved acceptance based on both US FDA-regulatory clearance and international-based (ISHLT) guideline acceptance - to effectively "rule-out" Moderate-Severe Grade 3A (2R) TCMR after heart transplantation and decrease the clinical necessity for surveillance endo-myocardial biopsy (EMB). Using Quantitative real-time polymerase chain reaction (qRT-PCR), individual transcripts of mRNA from PBMC are measured for the 20 genes designated for this test from an original 252 array of candidate genes. Encompassed in the AlloMap ${ }^{\circledR}$ array, there are 11 genes identified by bioinformatics methodologies and an additional 9 genes that were added to the test algorithm for quality control analyses. Targeted specific genes relate to relevant immunologic processes such as steroid responsiveness (IL1R2, ITGAM, FLT3), platelet activation, programmed cell death and TLymphocyte priming (PDCD1, ITGA4), activation \& trafficking. AlloMap ${ }^{\circledR}$ algorithm thus transforms the GEP to an integer value or test Score ranging from 0 to 40 . For "Surveillance" post-OHT, GEP values differ normally between 2 -months (GEP < 30) and 6- months (GEP < 34), therefore guidelines address this issue for interpretation. The utility of a specific GEP or AlloMap ${ }^{\circledR}$ test Score, should be focused on the Negative Predictive Value (NPV) for the test result. For example, an AlloMap ${ }^{\circledR}$ test Score of 28 is associated with a NPV of $98.5 \%$, which indicates a $98.5 \%$ estimated probability that the patient is not experiencing current active cellular rejection.

During the Invasive Monitoring Attenuation through Gene Expression (IMAGE) trial, 602 patients who had undergone orthotopic heart transplantation (OHT) 6 months to 5 years previously, were monitored for rejection with GEP or with the use of routine surveillance EMB, in 
addition to clinical and echocardiographic assessments of allograft function. During a median follow-up of 19 months, patients who were monitored with GEP and those who underwent routine biopsies had similar 2-year cumulative rates for the composite primary outcomes (14.5\% and $15.3 \%$, respectively; $\mathrm{HR} 1.04$ [95\% Cl: 0.67-1.68). The 2-year rates of "all-cause mortality" were also similar in the two groups $(6.3 \%$ and $5.5 \%$, respectively). The patients who were monitored by GEP underwent fewer biopsies per person-year of follow-up than did patients who were monitored with the use of EMB as surveillance $(0.5$ versus $3.0, P<0.001)$ [22]. Subsequent analyses by Deng, et al. noted that intra-subject "GEP Variability" as defined by the standard deviation (SD) of patient's cumulative scores, offered further prognostic insights into future clinical quiescence versus allograft dysfunction or death with improved outcomes associated with less variability. This prognostic information was independent from and complementary to the original use of single gene expression profiling ordinal test scores to estimate the probability of histologically defined TCMR at the time of testing [23, 24].

Current investigations are underway to assess the utility of GEP after Kidney Transplantation in multi-modality testing (KidneyCare ${ }^{\circledR}$ ) in combination with measurements of percent donorderived cell-free DNA (\%dd-cfDNA) and an analytical artificial intelligence platform (iBOX®) for prognosis in the current Evaluation of Patient Outcomes From the Kidney Allograft Outcomes Allosure $\Theta$ Registry (OKRA) of 4000 transplant recipients [ClinicalTrials.gov: NCT03326076]. Indeed Suthanthiaran et al during the CTOT-4 NIH Study of Kidney transplantation, identified a 3-Gene signature (CD3 3 mRNA, IP-10 mRNA and 18s rRNA) in Urine which was then validated in an external data set to differentiate Acute Cellular Rejection (ACR) from Antibody-mediated Rejection (ABMR) from "Borderline ACR" and "Quiescence" of the allograft. This Gene Expression Profiling for Urine was not affected by presence of urinary tract infection. Overall, the AUC $=0.85(95 \% \mathrm{Cl}$ : 0.78-0.91) performance for the diagnostic molecular test [25].

Additionally, GEP for the interrogation of the allograft tissue per se, such as in the feasibility study (INTERCOMEX Study) of kidney allograft biopsies (i.e. "Molecular Microscope Diagnostic; $\mathrm{MMDx}^{\circledR}$ ) [26] has also offered promise in complementing the histopathologic interpretation of rejection after solid organ transplantation [27-29].

\section{Donor-Derived Cell-free DNA Surveillance for Allograft "Tissue Injury" after Solid Organ Transplantation}

Recently, plasma donor-derived cell-free DNA (dd-cfDNA) has been reported as increased during "lung allograft injury" and associated with episodes of TCMR or lung allograft infection [30, 31]. Donor-derived cell-free DNA has been extensively investigated as a Biomarker of "allograft tissue injury" and validated for differentiation of TCMR or ABMR versus Quiescence after Kidney [32-37] and heart transplantation [38]. Cell-free DNA represents double-stranded DNA fragments of approximately 100-200 base-pairs that result from apoptosis, necrosis or release of nuclear DNA into circulation. While in circulation, these fragments have a short $T_{1 / 2}$ of approximately 30 minutes to 1.5 hours, due to rapid hepatic and renal clearance. Thus, dd-cfDNA offers the opportunity for real-time noninvasive assessment of "allograft tissue injury" and potential immunologically-mediated events. Indeed, Agbor-Enoh, et al., while utilizing shotgun sequencing techniques (that require genotyping of both allograft donor and recipient), described correlation of the "upper tertile" of the initial 3-month median level for dd-cfDNA after lung transplant (LT) 
and an approximately 6.6-fold increased risk for subsequent "allograft failure". The literature is less well defined, however, for the "threshold value" for dd-cfDNA and clinical utility as surveillance for lung allograft rejection and/or infection versus quiescence, while threshold values may differ significantly for dd-cfDNA across the spectrum of solid organ transplants [30, 37-40] and summarized in Table 1 . Preliminary studies from Stanford University and the NIH have reported dd-cfDNA levels in stable reference post-LT populations of approximately $0.4 \%$ [30, 39]. Next Generation Sequencing (NGS) that targets donor and recipient genomic disparity for single nucleotide polymorphisms (SNPs) provides the platform to differentiate and measure percentage of circulating donor-derived cell-free DNA but without requirement for genomic sequencing of the allograft donor. A validated and precise clinical-grade NGS assay (AlloSure ${ }^{\circledR}$ v3.0) has been developed with a linear detection range of $0.12-16 \%$ and across-run coefficient of variation (CV) of $4.6 \%$, therefore permitting further evaluation and assessments of clinical validation and utility after lung transplantation [33].

Assessment of dd-cfDNA (AlloSure ${ }^{\circledR}$; Prospera ${ }^{\circledR}$ ) in plasma after Kidney transplant (KT) is wellestablished for surveillance and currently reimbursed by Content Management System (CMS) for Medicare \& Medicaid Services. In a pivotal multi-center, prospective investigation utilizing ddcfDNA (AlloSure ${ }^{\circledR}$ ) in the Diagnose Acute Rejection After Kidney Transplant (DART) Study, a threshold dd-cfDNA of $0.21 \%$, which was the median value for healthy / stable KT recipients, the Negative Predictive Value (NPV) for active rejection, was $95 \%$ i.e. a $95 \%$ probability that the patient has no active rejection at time of testing. Further, using a threshold of $2.9 \%$, the Positive Predictive Value (PPV) was $89 \%$ for detection of ABMR in the context of concurrent evidence of HLA Class I or II DSA, i.e. 89\% probability for the presence of antibody-mediated allograft rejection. This finding is particularly striking since our understanding has recently expanded to consider the presence of ABMR even in the absence of detectable HLA DSA that can relate to auto-antibodies (e.g. AT1R, EC, MICA, etc.) [12-15]. Additionally, patients who have required re-transplant with KT, despite the presence of more than one implanted kidney, nevertheless can be monitored with ddcfDNA as surveillance [41]. Monitoring of serial dd-cfDNA can also permit real-time assessment for responses to therapy for rejection, since values typically decrease to prior "baseline" over the ensuing 2-3 months [32]. Although a "threshold" dd-cfDNA of $1.0 \%$ should prompt a clinical consideration of T-Cell Mediated Rejection (TCMR), increasing data suggests a continuum for this Biomarker as representing "allograft injury" such that analysis of serial measurements may provide additional insights. Indeed, a recent multi-center investigation by Stites et al, utilizing a "threshold" dd-cfDNA of $0.5 \%$ concurrent with a performed kidney biopsy which had demonstrated the ambiguous histopathologic diagnoses of "Borderline" or TCMR1A by the 2017 Banff consensus criteria [42], demonstrated worsened clinical outcomes for the "High" dd-cfDNA cohort compared with the similar pathologic diagnosis associated with a "Low" dd-cfDNA (i.e. $<0.5 \%)$. The "High" cohort experienced decrement in mean eGFR of $-8.5 \%$ over the ensuing 3-6 months in contrast to the "Low" cohort whereupon renal function was unchanged. Further, the "High" cohort experienced increased incidence for subsequent development of ABMR or recurrent TCMR [43]. Recently, utilizing a different NGS methodology with massively multiplex PCR of SNPS, measurement of dd-cfDNA (Prospera ${ }^{\circledR}$ ) had also been demonstrated with analytical [35] and clinical validation and attaining CMS reimbursement based on a retrospective analysis from a single-center biorepository of plasma samples [36]. Clinical utility with this latter assay awaits 
further prospective and multi-center evaluation in the anticipated PROspera Kidney Transplant ACTIVE Rejection Assessment Registry (ProActive; ClinicalTrials.gov: NCT04091984).

Table 1 Surveillance molecular diagnostics after organ transplant. GEP = Gene Expression Profiling (peripheral blood mononuclear cells; dd-cf-DNA = Donor-derived Cell-free DNA (peripheral blood plasma); DSA = Donor-specific HLA Allo-antibodies; $\mathrm{CMV}=$ Cytomegalovirus; $\mathrm{EMB}=$ Endomyocardial biopsies; NPV $=$ Negative Predictive Value (Probability that a negative test result represents no evidence of rejection); PPV = Positive Predictive Value (Probability that a Positive Test result represents allograft rejection). TMCR / Borderline = Borderline (Banff Grade TMCR1A / Borderline) T-Cell Mediated Rejection. $\mathrm{ABMR}=$ Antibody-Mediated rejection .

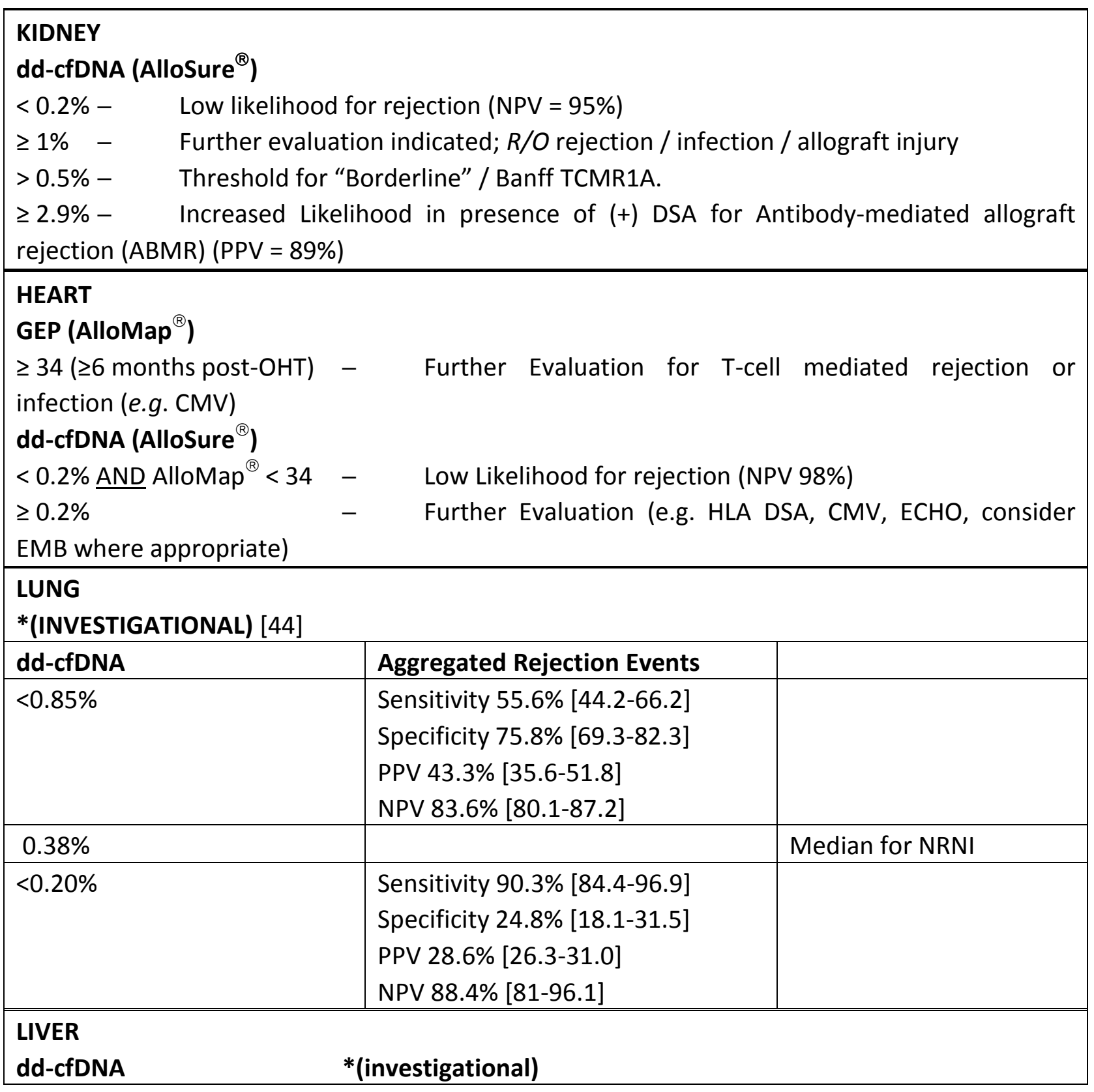

*Limited clinical data to establish "optimal thresholds" for current clinical use. 
Measurement of dd-cf-DNA (AlloSure ${ }^{\circledR}$-HEART) after orthotopic heart transplant (OHT) may complement the surveillance data as derived from "Gene Expression Profiling" (AlloMap ${ }^{\circledR}$ ) monitoring [Figure 1]. As derived from three clinical studies encompassing a total $362 \mathrm{OHT}$ recipients and 744 paired EMB samples, the "baseline" dd-cf-DNA in a reference population was $0.06 \%$ while a "threshold" of $0.2 \%$ has been advanced for surveillance of TCMR and ABMR [Utility of Donor-Derived Cell Free DNA in Association with Gene Expression Profiling (D-OAR) Registry; ClinicalTrials.gov: NCT02178943] while further data is forthcoming in a current the multi-center Surveillance HeartCare ${ }^{\circledR}$ Outcomes Registry [(SHORE); ClinicalTrials.gov: NCT03695601].

\section{"Multi-modality Surveillance" after Solid Organ Transplant}
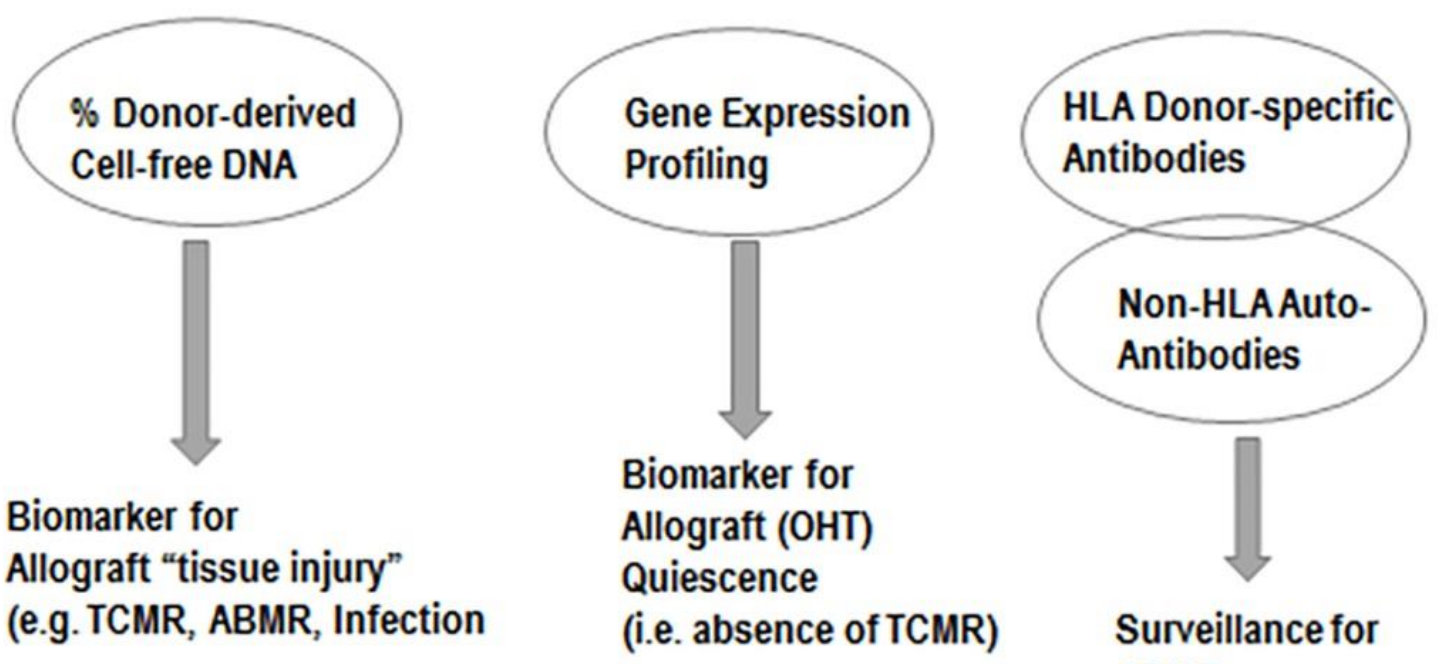

Surveillance for ABMR

\section{BIOPSY ALLOGRAFT (?)}

Figure 1 "Multi-Modality Surveillance" after Solid Organ Transplantation. Complementary analytes with clinical utility as "surveillance" for diverse complications involving the allograft including T-Cell Mediated Rejection (TCMR), Antibody-Mediated Rejection (ABMR) or Infection. Gene Expression Profiling (GEP; AlloMap ${ }^{\circledR}$ ) is currently only FDA-cleared and CMS reimbursed as Surveillance for TCMR or Quiescence after Orthotopic Heart Transplantation (OHT) [refer Text] and recommended per International Society for Heart and Lung Transplant (ISHLT) Guidelines (Level II; Grade B Evidence) [45]. Donor-Derived Cell-free DNA permits complementary assessment of potential "Allograft Tissue Injury" that may relate to complications including TCMR, ABMR (HLA or Non-HLA mediated), allograft associated infection or ischemia. Immunogenetic Laboratory assessments using solid-phase assays for detection of donor-specific HLA Allo-antibodies (DSA) or Non-HLA auto-antibodies (e.g. antiAngiotensin-2 type-1 receptor, anti-Endothelial cell, anti- Major Histocompatibility Complex class I chain-related molecule A (MICA) complements the assessment for potential ABMR. 


\section{Transplant Proteomics for Biomarker Discovery and Solid Organ Transplantation}

The Human Protein Organization launched the Human Protein Project hence proteomic methodologies have been implemented in the field of discovery and validation of biomarkers after solid organ transplantation [46, 47]. Urinary Biomarkers for surveillance hold promise for assessment of the Kidney allograft as demonstrated by Schaub et al. who had reported an increase of the chemokines, CXCL9 and CXCL10 protein, in the urine of patients with acute interstitial infiltration and tubuliitis during both subclinical and clinical TCMR [47]. Additional investigations have reported an increase of UMOD, SERPINF1 and CD44 in the urine of patients during active acute rejection. An integrative strategy that utilized both Gene Expression Profiling and peptidomics data, a 40-peptide panel including UMOD has been reported as specific for acute rejection during urine surveillance $[44,47,48]$.

In the lung transplant realm, considerable research as elucidated the relevance of cytokine and chemokine biology as contributing to the pathogenesis of a continuum from acute cellular rejection to Chronic Lung Allograft Dysfunction (CLAD) or Bronchiolitis Obliterans Syndrome (BOS) [49-51].

Across solid-organ transplant fields, ongoing research holds considerable promise and currently focuses on validation and clinical utility of protein and peptide Biomarkers via proteome analyses by high-throughput assays and advanced bioinformatics analyses. Indeed, recent developments in profiling of biomolecules utilizing "omics" methodologies have provided novel platforms for further Biomarker discovery.

\section{Summary}

Biomarker surveillance after solid organ transplant is an advancing field with promises for further elucidation through high-throughput analyses and "omics" technologies. To date, Gene Expression Profiling (AlloMap ${ }^{\circledR}$ ) is the only FDA-cleared genomic assay for surveillance of Moderate-Severe TCMR versus Allograft Quiescent after OHT. Clinical validity and utility have been established after Kidney and Heart transplantation, for analysis of donor-derived cell-free DNA in assessing for "Allograft Tissue Injury" as may occur during TCMR, ABMR (HLA or Non-HLA mediated) or allograft-associated infection. These genomic analytes are further being evaluated across the spectrum of solid organ transplantation. "Multi-Modality Surveillance" as depicted in Figure 1, is currently within the armamentarium and practice algorithms of the transplant center specialist however, such methodologies that are performed on peripheral blood samples, can be obtained during routine laboratory surveillance and should be widely applicable to the transitioning of routine medical care, that is increasingly relegated to the General Practitioner. Furthermore, laboratory noninvasive Biomarker surveillance may avoid unnecessary protocol biopsy procedures in a predominance of transplanted patients. Such monitoring may similarly prove invaluable as a means to avoid infectious contagion exposures during scheduled routine medical office appointments, in particular such as during times of heightened risk such as the SARS-CoV-2 (CoVid-19) pandemic. 


\section{Author Contributions}

Initial draft of manuscript written by Allison Ramsey and David Ross equally. Manuscript revision and edits performed equally by listed co-authors.

\section{Funding}

No funding was involved in the writing of this review article.

\section{Competing Interests}

The authors have no financial disclosures relevant to the writing of this review article. Coauthor (djr) is employed by CareDx, Inc.

\section{References}

1. Liapakis A, Formica RN, Levitsky J. Solid organ transplantation of viral hepatitis C positive donor organs into viral hepatitis $C$ negative recipients. Curr Opin Organ Transplant. 2018; 23: 257-263.

2. Gentile C, Van Deerlin VM, Goldberg DS, Reese PP, Hasz RD, Abt P, et al. Hepatitis C virus genotyping of organ donor samples to aid in transplantation of HCV-positive organs. Clin Transplant. 2018; 32.

3. Van Raemdonck D, Nevens F, Van Cleemput J, Vos R, Neyrinck A, Verleden GM. Fishing in the thoracic organ donor pool: What next if the catch of the day got infected with hepatitis $C$ virus? J Thorac Cardiovasc Surg. 2019.

4. Alegre ML, Florquin S, Goldman M. Cellular mechanisms underlying acute graft rejection: Time for reassessment. Curr Opin Immunol. 2007; 19: 563-568.

5. Wang S, Zhang C, Wang J, Yang C, Xu M, Rong R, et al. Endothelial cells in antibody-mediated rejection of kidney transplantation: Pathogenesis mechanisms and therapeutic implications. J Immunol Res. 2017; 2017: 8746303.

6. Wang S, Zhang C, Wang J, Yang C, Xu M, Rong R, et al. Corrigendum to "endothelial cells in antibody-mediated rejection of kidney transplantation: Pathogenesis mechanisms and therapeutic implications". J Immunol Res. 2019; 2019: 9691679.

7. Valenzuela NM, Reed EF. Antibody-mediated rejection across solid organ transplants: Manifestations, mechanisms, and therapies. J Clin Invest. 2017; 127: 2492-2504.

8. Nakagiri T, Inoue M, Minami M, Shintani Y, Okumura M. Immunology mini-review: The basics of $T(H) 17$ and interleukin-6 in transplantation. Transplant Proc. 2012; 44: 1035-1040.

9. Serody JS, Hill GR. The IL-17 differentiation pathway and its role in transplant outcome. Biolo Blood Marrow Transplant. 2012; 18: S56-S61.

10. Sumpter TL, Wilkes DS. Role of autoimmunity in organ allograft rejection: A focus on immunity to type $\mathrm{V}$ collagen in the pathogenesis of lung transplant rejection. Am J Physiol Lung Cell Mol Physiol. 2004; 286: L1129-L1139.

11. Ciszek M, Foroncewicz B, Mucha K, Zochowska D, Ziarkiewicz-Wroblewska B, Krawczyk M, et al. Anti-HLA and anti-MICA antibodies in liver transplant recipients: Effect on long-term graft survival. Clin Dev Immunol. 2013; 2013: 828201. 
12. Sapak M, Chrenova S, Tirpakova J, Zilinska Z, Durmanova V, Shawkatova I, et al. Donor nonspecific mica antibodies in renal transplant recipients. Immunobiology. 2014; 219: 109-112.

13. Risti M, Bicalho MD. MICA and NKG2D: Is there an impact on kidney transplant outcome? Front Immunol. 2017; 8: 179.

14. Banasik M, Boratynska M, Koscielska-Kasprzak K, Kaminska D, Bartoszek D, Zabinska M, et al. The influence of non-HLA antibodies directed against angiotensin II type 1 receptor (AT1R) on early renal transplant outcomes. Transpl Int. 2014; 27: 1029-1038.

15. Gareau AJ, Wiebe C, Pochinco D, Gibson IW, Ho J, Rush DN, et al. Pre-transplant AT1R antibodies correlate with early allograft rejection. Transpl Immunol. 2018; 46: 29-35.

16. Colvin M, Smith JM, Hadley N, Skeans MA, Uccellini K, Goff R, et al. OPTN/SRTR 2018 annual data report: Heart. Am J Transplant. 2020; 20 Suppl s1: 340-426.

17. Hart A, Smith JM, Skeans MA, Gustafson SK, Wilk AR, Castro S, et al. OPTN/SRTR 2018 annual data report: Kidney. Am J Transplant. 2020; 20 Suppl s1: 20-130.

18. Valapour M, Lehr CJ, Skeans MA, Smith JM, Uccellini K, Goff R, et al. OPTN/SRTR 2018 annual data report: Lung. Am J Transplant. 2020; 20 Suppl s1: 427-508.

19. Kwong A, Kim WR, Lake JR, Smith JM, Schladt DP, Skeans MA, et al. OPTN/SRTR 2018 annual data report: Liver. Am J Transplant. 2020; 20 Suppl s1: 193-299.

20. Lander ES, Linton LM, Birren B, Nusbaum C, Zody MC, Baldwin J, et al. Initial sequencing and analysis of the human genome. Nature. 2001; 409: 860-921.

21. Venter JC, Adams MD, Myers EW, Li PW, Mural RJ, Sutton GG, et al. The sequence of the human genome. Science. 2001; 291: 1304-1351.

22. Pham MX, Teuteberg JJ, Kfoury AG, Starling RC, Deng MC, Cappola TP, et al. Gene-expression profiling for rejection surveillance after cardiac transplantation. N Engl J Med. 2010; 362: 1890-1900.

23. Deng MC, Elashoff B, Pham MX, Teuteberg JJ, Kfoury AG, Starling RC, et al. Utility of gene expression profiling score variability to predict clinical events in heart transplant recipients. Transplantation. 2014; 97: 708-714.

24. Crespo-Leiro MG, Stypmann J, Schulz U, Zuckermann A, Mohacsi P, Bara C, et al. Performance of gene-expression profiling test score variability to predict future clinical events in heart transplant recipients. BMC Cardiovasc Disord. 2015; 15: 120.

25. Suthanthiran $M$, Muthukumar T. Urinary-cell mRNA and acute kidney-transplant rejection. $N$ Engl J Med. 2013; 369: 1860-1861.

26. Halloran PF, Reeve J, Akalin E, Aubert O, Bohmig GA, Brennan D, et al. Real time central assessment of kidney transplant indication biopsies by microarrays: The intercomex study. Am J Transplant. 2017; 17: 2851-2862.

27. Weigt SS, Wang X, Palchevskiy V, Patel N, Derhovanessian A, Shino MY, et al. Gene expression profiling of bronchoalveolar lavage cells during aspergillus colonization of the lung allograft. Transplantation. 2018; 102: 986-993.

28. Jonigk D, Izykowski N, Rische J, Braubach P, Kuhnel M, Warnecke G, et al. Molecular profiling in lung biopsies of human pulmonary allografts to predict chronic lung allograft dysfunction. Am J Pathol. 2015; 185: 3178-3188.

29. Sigdel T, Nguyen M, Liberto J, Dobi D, Junger H, Vincenti F, et al. Assessment of 19 genes and validation of CRM gene panel for quantitative transcriptional analysis of molecular rejection and inflammation in archival kidney transplant biopsies. Front Med (Lausanne). 2019; 6: 213. 
30. De Vlaminck I, Martin L, Kertesz M, Patel K, Kowarsky M, Strehl C, et al. Noninvasive monitoring of infection and rejection after lung transplantation. Proc Natl Acad Sci U S A. 2015; 112: 13336-13341.

31. Zou J, Duffy B, Slade M, Young AL, Steward N, Hachem R, et al. Rapid detection of donor cell free DNA in lung transplant recipients with rejections using donor-recipient HLA mismatch. Hum Immunol. 2017; 78: 342-349.

32. Bloom RD, Bromberg JS, Poggio ED, Bunnapradist S, Langone AJ, Sood P, et al. Cell-free DNA and active rejection in kidney allografts. J Am Soc Nephrol. 2017; 28: 2221-2232.

33. Grskovic M, Hiller DJ, Eubank LA, Sninsky JJ, Christopherson C, Collins JP, et al. Validation of a clinical-grade assay to measure donor-derived cell-free DNA in solid organ transplant recipients. J Mol Diagn. 2016; 18: 890-902.

34. Bromberg JS, Brennan DC, Poggio E, Bunnapradist S, Langone A, Sood P, et al. Biological variation of donor-derived cell-free DNA in renal transplant recipients. J Appl Lab Med. 2017; 2: 309-321.

35. Altug $\mathrm{Y}$, Liang $\mathrm{N}$, Ram R, Ravi $\mathrm{H}$, Ahmed E, Brevnov $\mathrm{M}$, et al. Analytical validation of a singlenucleotide polymorphism-based donor-derived cell-free DNA assay for detecting rejection in kidney transplant patients. Transplantation. 2019; 103: 2657-2665.

36. Sigdel TK, Archila FA, Constantin T, Prins SA, Liberto J, Damm I, et al. Optimizing detection of kidney transplant injury by assessment of donor-derived cell-free DNA via massively multiplex PCR. J Clin Med. 2018; 8.

37. Jordan SC, Bunnapradist S, Bromberg JS, Langone AJ, Hiller D, Yee JP, et al. Donor-derived cellfree DNA identifies antibody-mediated rejection in donor specific antibody positive kidney transplant recipients. Transplant Direct. 2018; 4: e379.

38. Khush KK, Patel J, Pinney S, Kao A, Alharethi R, DePasquale E, et al. Noninvasive detection of graft injury after heart transplant using donor-derived cell-free DNA: A prospective multicenter study. Am J Transplant. 2019; 19: 2889-2899.

39. Agbor-Enoh S, Wang Y, Tunc I, Jang MK, Davis A, De Vlaminck I, et al. Donor-derived cell-free DNA predicts allograft failure and mortality after lung transplantation. EBioMedicine. 2019; 40: 541-553.

40. Gielis EM, Ledeganck KJ, Dendooven A, Meysman P, Beirnaert C, Laukens K, et al. The use of plasma donor-derived, cell-free DNA to monitor acute rejection after kidney transplantation. Nephrol Dial Transplant. 2019.

41. Mehta SG, Chang JH, Alhamad T, Bromberg JS, Hiller DJ, Grskovic M, et al. Repeat kidney transplant recipients with active rejection have elevated donor-derived cell-free DNA. Am J Transplant. 2019; 19: 1597-1598.

42. Loupy A, Haas M, Solez K, Racusen L, Glotz D, Seron D, et al. The banff 2015 kidney meeting report: Current challenges in rejection classification and prospects for adopting molecular pathology. Am J Transplant. 2017; 17: 28-41.

43. Stites $E$, Kumar D, Olaitan O, Swanson SJ, Leca N, Weir M, et al. High levels of dd-cfDNA identifies patients with TCMR $1 \mathrm{~A}$ and borderline allograft rejection at elevated risk of graft injury. Am J Transplant. 2020.

44. Ling XB, Sigdel TK, Lau K, Ying L, Lau I, Schilling J, et al. Integrative urinary peptidomics in renal transplantation identifies biomarkers for acute rejection. J Am Soc Nephrol. 2010; 21: 646653. 
45. Francis GS, Greenberg $B H$, Hsu DT, Jaski BE, Jessup $M$, LeWinter $M M$, et al. ACCF/AHA/ACP/HFSA/ISHLT 2010 clinical competence statement on management of patients with advanced heart failure and cardiac transplant: A report of the ACCF/AHA/ACP task force on clinical competence and training. J Am Coll Cardiol. 2010; 56: 424-453.

46. Rifai N, Gillette MA, Carr SA. Protein biomarker discovery and validation: The long and uncertain path to clinical utility. Nat Biotechnol. 2006; 24: 971-983.

47. Norden $A G$, Rodriguez-Cutillas $P$, Unwin RJ. Clinical urinary peptidomics: Learning to walk before we can run. Clin Chem. 2007; 53: 375-376.

48. Sigdel TK, Lau K, Schilling J, Sarwal M. Optimizing protein recovery for urinary proteomics, a tool to monitor renal transplantation. Clin Transplant. 2008; 22: 617-623.

49. Shino MY, Weigt SS, Li N, Palchevskiy V, Derhovanessian A, Saggar R, et al. CXCR3 ligands are associated with the continuum of diffuse alveolar damage to chronic lung allograft dysfunction. Am J Respir Crit Care Med. 2013; 188: 1117-1125.

50. Belperio JA, Keane MP, Burdick MD, Gomperts B, Xue YY, Hong K, et al. Role of CXCR2/CXCR2 ligands in vascular remodeling during bronchiolitis obliterans syndrome. J Clin Invest. 2005; 115: 1150-1162.

51. DerHovanessian A, Wallace WD, Lynch JP, 3rd, Belperio JA, Weigt SS. Chronic lung allograft dysfunction: Evolving concepts and therapies. Semin Respir Crit Care Med. 2018; 39: 155-171.

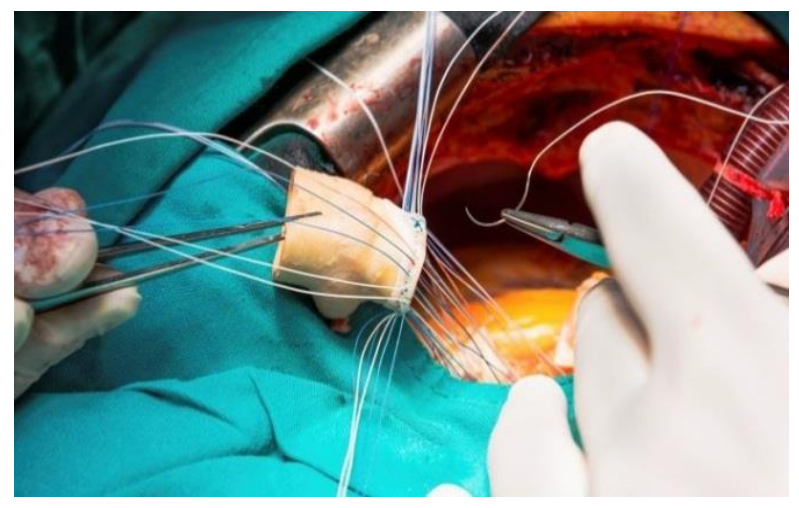

Enjoy OBM Transplantation by:

1. Submitting a manuscript

2. Joining in volunteer reviewer bank

3. Joining Editorial Board

4. Guest editing a special issue

For more details, please visit:

http://www.lidsen.com/journals/transplantation 